\title{
Revisiting Primary Care's Critical Role in Achieving Health Equity: Pisacano Scholars' Reflections from Starfield Summit II
}

\author{
Brian Park, MD, MPH, Anastasia J. Coutinho, MD, MHS, Noemi Doohan, MD, PhD, \\ Jonathan Jimenez, MD, MPH, Sara Martin, MD, Max Romano, MD, MPH, \\ Diana Wobler, MD, and Jennifer DeVoe, MD, DPhil
}

The second Starfield Summit was held in Portland, Oregon, in April 2017. The Summit addressed the role of primary care in advancing health equity by focusing on 4 key domains: social determinants of health in primary care, vulnerable populations, economics and policy, and social accountability. Invited participants represented an interdisciplinary group of primary care clinicians, researchers, educators, policymakers, community leaders, and trainees. The Pisacano Leadership Foundation was one of the Summit sponsors and held its annual leadership symposium in conjunction with the Summit, enabling several Pisacano Scholars to attend the Summit. After the Summit, a small group of current and former Pisacano Scholars formed a writing group to highlight key themes and implications for action discussed at the Summit. The Summit resonated as a call to action for primary care to move beyond identifying existing health inequities and toward the development of interventions that advance health equity, through education, research, and enhanced community partnerships. In doing so, the Summit aimed to build on the foundational work of Dr. Starfield, challenging us to explore the significant role of primary care in truly achieving health equity. (J Am Board Fam Med 2018;31:292-302.)

Keywords: Health Equity, Leadership, Primary Health Care, Social Determinants of Health, Social Responsibility, Vulnerable Populations

From April 22 to 25, 2017, 181 primary care experts and advocates convened in Portland, Oregon, to share ideas during the second Starfield Summit. Named in honor of Professor Barbara Starfield, a

\footnotetext{
This article was externally peer reviewed.

Submitted 1 July 2017; revised 29 September 2017; accepted 20 October 2017.

From the Combined Family Medicine \& Preventive Medicine Residency (BP) and the Department of Family Medicine (JD), Oregon Health \& Science University, Portland; the Santa Rosa Family Medicine Residency, Santa Rosa, CA (AJC; SM); the Department of Family and Community Medicine, University of California-Davis, Sacramento (ND); the Duke University Family Medicine Residency, Durham, NC (JJ); Bloomberg School of Public Health - General Preventive Medicine Residency, Johns Hopkins University, Baltimore, MD (MR); MedStar Franklin Square Medical Center, Baltimore (MR); the Brown Family Medicine Residency Program, Memorial Hospital of Rhode Island, Pawtucket (DW).

Funding: none.

Conflict of interest: none declared.

Corresponding author: Brian Park, MD MPH, Department of Family Medicine, Oregon Health \& Science University, Mailcode FM, 3181 SW Sam Jackson Park Rd, Portland, OR 97239 (E-mail: parbr@ohsu.edu).
}

pediatrician and health services researcher who devoted her career to advancing the role of primary care globally, the Starfield Summit aims to build on her legacy by optimizing the primary care function. ${ }^{1}$ Whereas the inaugural Starfield Summit in 2016 focused on payment, measurement, and new primary care models ${ }^{2}$, this second Summit focused on the role of primary care in achieving health equity.

The Summit was hosted and organized by $\mathrm{OCHIN}^{3}$ and the Department of Family Medicine at Oregon Health \& Science University, and cosponsored by the American Board of Family Medicine Foundation, Family Medicine for America's Health, the North American Primary Care Research Group, and the Pisacano Leadership Foundation (PLF). Key documents and videos of speakers from the Starfield Summit are available online. ${ }^{4}$ Participants represented an interdisciplinary group and included primary care clinicians, researchers, 
educators, policymakers, community leaders, and trainees. Appendix 1 lists the Summit attendees.

\section{Starfield Summit II Structure}

Seventeen thought-leaders were invited to present 5-minute Ignite-style talks ${ }^{5}$ in 1 of 4 domains: social determinants of health (SDHs), vulnerable populations, economics and policy, and social accountability. The presentations stimulated discussion for future actions in 90-minute breakout sessions on each topic. Each speaker had a moderator to facilitate these discussions, during which themes and ideas for action were captured by designated note-takers. These insights were then shared with the larger group. On the final day, an action-planning meeting was held to identify next steps for integrating health equity work into primary care. Appendix 2 outlines the Summit schedule. A third Starfield Summit, addressing metrics in primary care, was held October 4 to 6, 2017.

\section{The PLF and Its Role in the Summit}

The PLF was created by the American Board of Family Medicine in 1991 to develop leaders in family medicine. It awards scholarships to medical students entering the specialty of family medicine and invites current and former scholars (alumni) to participate in an annual leadership symposium. A total of 32 current and former Pisacano Scholars attended the 2017 Summit. After the Pisacano symposium and the Summit, the authors-all Pisacano Scholars or alumni-formed a writing group to summarize highlights from the Summit and contribute to ongoing conversations about health equity and the future of primary care in the United States.

\section{PLF Leadership Symposium: Community Organizing}

The 2017 PLF symposium was held the day before the Summit and focused on community organizing as a mechanism to address health equity, a recommendation supported by the National Academies of Sciences, Engineering, and Medicine. ${ }^{6}$ The symposium was organized by Pisacano Scholars (Nathan Kittle, Glenna Martin, Brian Park), in partnership with the Industrial Areas Foundation (Joe Chrastil, Luis Manriquez), the nation's largest community organizing body.
Community organizing aims to build collective power by identifying shared issues and interests, mobilizing resources, and implementing collectively set solutions in order to create social change. ${ }^{7}$ It has demonstrated success in influencing social policies, including education ${ }^{8}$, housing ${ }^{9}$, and poverty $^{10}$, and a recent initiative pointed to its impact on health. ${ }^{11}$ This approach was central to the original community health centers, leading to the development of cooperative farms, the creation of water sanitation systems, and the hiring of local residents to provide health professions pathways. $^{12,13}$ As the funding for community health centers became more dependent on fees for clinical services, their missions narrowed toward providing medical care alone. ${ }^{13}$ The full-day symposium trained Pisacano Scholars and alumni in community organizing, promoting the revival of these skills in their communities.

\section{Overview of the Summit Discussions}

The idea that health is larger than the provision of health care is not new. In 1849, Rudolf Virchow, the founder of social medicine, said, "For if medicine is really to accomplish its great task, it must intervene in political and social life." ${ }^{14}$ Primary care emerged to address health inequities by integrating clinical care, behavioral health, public health, and social services ${ }^{15}$; Drs. Emily and Sidney Kark developed the model of community-oriented primary care in rural South Africa in the $1940 \mathrm{~s}^{16}$, the US Folsom Commission report established "health as a community affair,"17 and Family Medicine was founded on countercultural principles of distributive justice and SDHs. ${ }^{18,19}$ The responsibility of primary care in health equity evolved over subsequent decades to the 1978 World Health Assembly in Alma Ata, where Dr. Halfdan Mahler, of the World Health Organization, declared, "[Primary care] forms an integral part both of the country's health system, of which it is the central function and main focus, and of the overall social and economic development of the community." 20

A quarter century later, Dr. Starfield provided evidence to support the impact of the primary care function toward this social justice ethos, demonstrating that a strong primary care foundation is associated with improved health equity. ${ }^{21,22}$ In a moving tribute during the Summit's opening ses- 
sion, Dr. Starfield's husband, Dr. Tony Holtzman, Emeritus Professor of Pediatrics at Johns Hopkins University, emphasized that Dr. Starfield's work on health equity tripled after the turn of the century, representing $7 \%$ of her total peer-reviewed publications before 2000 and $20 \%$ afterward. Her work showed that within and across countries, strong primary care foundations attenuated the impact of socioeconomic disparities on health ${ }^{21,22}$ Yet, Dr. Starfield was aware of the limitations of health care alone in addressing health disparities, writing in one of those seminal pieces after 2000, "Inequity is built into health systems."23

Professor David Williams, the keynote speaker at the Summit and a professor in public health and sociology at Harvard University, built on Dr. Starfield's critique, asserting that primary care has a responsibility to reach beyond health care and influence broader society in order to address health inequities. "Health care system reform," Dr. Williams stated, "is critical, but insufficient" to improve our nation's health, given structural inequities in our society, including but not limited to biological weathering ${ }^{24}$, racial and ethnic differences in income ${ }^{25,26}$, and disparities in SAT scores by family income. ${ }^{27}$

Significant barriers exist for the primary care community to respond to Dr. Starfield's and Dr. Williams's charge to achieve health equity, including a fee-for-service payment model that promotes volume over value ${ }^{28}$, the increasing demands placed on primary care providers ${ }^{29,30}$, and the country's lack of investment in social services. ${ }^{31,32}$ The United States subsequently fails to close the gap in health outcomes and to achieve the triple aimimproved population health outcomes and patient experience of care at lower costs ${ }^{33}$ - compared with other countries. ${ }^{34,35}$ These poor outcomes disproportionately burden minority and marginalized groups. ${ }^{36-38}$

This Starfield Summit aimed to advance the foundational work of Dr. Starfield by highlighting primary care "bright spots" advancing health equity. Each bright spot was organized within 4 of the Summit's domains, and each answered an essential question regarding how the primary care community could address inequities:

- SDH in primary care: If access to primary care alone is insufficient to address health equity ${ }^{39}$, what additional services can primary care systems provide to better address SDHs and improve outcomes?

- Vulnerable populations: How can primary care partner with social services and community organizations to address unjust societal structures, thereby improving health?

- Economics and policy: How do systems pay for and measure metrics that support a primary care infrastructure that addresses health equity?

- Social accountability: How, and to whom, are primary care institutions held accountable for clinical services, education, research, and policies?

This report emphasizes key Summit bright spots and participant discussion themes, culminating with recommendations from the Pisacano writing group for how to promote effective SDH interventions that could be scaled to a variety of primary care settings. ${ }^{40}$

\section{Summarizing the Summit: Facts, Themes, and Implications SDHs in Primary Care}

Primary care can play an instrumental role in identifying and addressing SDHs; key Summit themes supporting the role of primary care in SDHs are outlined in Table 1. Dr. Laura Gottlieb discussed how electronic health records (EHRs) enable social data to be monitored in clinical practice and offer the opportunity to address these factors at the point of care. ${ }^{41,42}$ Although many practices capture some social factors (eg, race/ethnicity, address, tobacco use), collection is not standardized, comprehensive, nor designed to affect care delivery. ${ }^{43,44}$ In response, the National Academy of Medicine recommended 11 social and behavioral domains to be collected and documented in EHRs, some of which are now recommended by multiple health organizations, including the American Academy of Pediatrics $^{45}$ and the Center for Medicare \& Medicaid Services Innovation Center. ${ }^{46}$

Furthermore, Dr. Lloyd Michener encouraged ingesting community-level data ("community vital signs") into EHRs to better understand a patient's neighborhood context and potentially to guide the development of coordinated, multisectoral interventions. ${ }^{47,48}$ For example, the Just for Us program was launched after identifying increased needs of elderly patients in low-income housing in Durham, North Carolina ${ }^{49}$, partnering primary care, county 
Table 1. Brainstorming Themes Regarding Social Determinants of Health and Primary Care, as Discussed at the 2017 Starfield Summit

Theme from Starfield Summit Participants' Discussion on SDHs

Representative Statements from Group Discussion Reflecting Theme

Addressing SDHs is a responsibility of primary care.

Innovations for addressing SDHs are outpacing the evidence.

Qualitative data analysis of patient stories should be used to identify and address SDHs.

Relational leadership and community organizing are important, underutilized tools to address SDHs.

CHIPs create needed links across the medical-social neighborhood.

Policy changes increasing payment and resources for addressing $\mathrm{SDH}$ are necessary.

"SDHs frame the health problems of our patients."

"In the United States, health care is used as a 'Trojan horse' for social services [because it is more acceptable]."

"Data are needed to understand which SHDs are priorities to be addressed by primary care providers and how best to do so."

"Abundant emerging evidence supports the effect of SDHs on health outcomes/disparities, but less evidence exists for clinical interventions to mitigate SDHs."

"Intermediate outcome metrics for SDH interventions must be developed and validated. Long-term mortality and intermediate health biomarkers may be inappropriate metrics of SDH interventions."

"Public health and population health data should be better integrated at the point of care."

"If the patient is at the center of health care, we need to hear about the patient experience."

"Patient stories can influence health care models and payment. Primary care should inform patients about the impact their stories can have."

"The act of sharing a story can be therapeutic in itself."

"Coalitions start as 1 or 2 connections, and then they connect with others. Success depends on history and the process undertaken."

"Social movements and relational approaches do not play to the technical expertise as health professionals. We can embrace that as an opportunity for those with whom we partner."

"Academic medical faculty may feel less comfortable teaching about community organizing, but we can partner with community organizations to learn."

"CHIPs create intentional strategies and tactical plans."

"In Oregon, everyone-hospitals, nonprofits, etc.-contributed to the CHIP. It was necessary to bring everyone together."

"Metrics are universal, so [CHIPs] can be universal too. They can cross ideological divides, like the cost of health care, and encompass SDHs and workforce issues."

"The fee-for-service payment model does not promote addressing SDHs."

"Attempts to address SDHs without proper resources in place could do more harm than good."

"Clinics need staff to connect patients with resources and to follow up to ensure coordination with these services."

CHIP, community health improvement plan; SDH, social determinant of health.

health departments, and housing agencies to bridge clinical medicine with public health and social services. Other bright spots that were highlighted include documenting patient experiences in the $\mathrm{EHR}^{50}$ and supplementing monitoring patients' SDHs in the EHR, with social needs identified by community advisory councils. ${ }^{51}$ Summit speakers and participants recognized the need to prioritize which SDH-related metrics are most critical to monitor, to develop replicable interventions for patients screening positive for SDHs, and to test payment models that enable SDH activities in primary care.

\section{Vulnerable Populations}

Social determinants of equity refer to societal inequities in opportunities that lead to disparities. ${ }^{52}$ 
Table 2. Brainstorming Themes Regarding Vulnerable Populations, as Discussed at the 2017 Starfield Summit

Theme from Starfield Summit Participants'

Discussion on Vulnerable Populations

Representative Statements from Group Discussion Reflecting Theme

Health care should recruit and train providers to understand the needs of their community.

Systemic injustices are institutional and structural, not just interpersonal.

The elimination of injustice requires the solidarity of the advantaged.

Data collection of various social factors helps us better understand health inequity and intersectionality.

Collection of SDH data is insufficient alone; various factors contribute to interpreting data responsibly.

The system may need initial unequal investments to create equity for all.

Policies should support a workforce working with vulnerable populations.

"Rural providers often grew up in rural communities; we should be recruiting trainees from these areas to return to these areas."

"Medical school admissions should systematically choose trainees most likely to serve the needs of populations."

"Most medical schools have limited curricula addressing vulnerable populations and social determinants of health."

"Empowerment of the individual alone cannot be the only answer-the power of unjust structures often overwhelms individuals."

"We cannot talk about health disparities without talking about racism. There is a historic systemic inequity society is still trying to overcome."

"We need to consider oppressive societal forces, as opposed to focusing on vulnerable individuals or populations."

"Physician advocacy for health and rights of vulnerable populations is important."

"What happens to marginalized groups impacts all of society, and if injustices like racism and poverty are to be eradicated, those of us who are privileged need to do our part."

"There is a lack of knowledge and willingness for physicians to unpack what upholds our privilege, and this perpetuates the -isms."

"There must be recognition that certain vulnerabilities are currently invisible. Patients need to be asked about these."

"As certain vulnerable groups become more isolated, we must develop new methods for reaching them."

"When social data is collected, it needs to be correct, useful, and accurate. It's not 'Asian,' but Korean, Vietnamese, Taiwanese, etc."

"Qualitative data is important for understanding patients and their experiences better. Open ended questions such as 'Who are you?' may provide more useful information."

"Analysis of a large single subpopulation eliminates the individual challenges faced by those who may fall into multiple vulnerable groups."

"There is missing or vague data that prevents informed decisions. For example, socioeconomic status is not often systematically queried, and immigration status might not be shared due to stigma and fear."

"Categories are not necessarily stagnant; for example, sexual orientation or socioeconomic status can change for individuals over time."

"Academic health centers should make disproportionately higher investments in vulnerable populations they care for."

"We need to redistribute privilege. Dismantling systemic and historic inequities is a health intervention, just like treating pneumonia."

"Often, making policies for one subgroup can cause others to feel left out or increasingly marginalized."

"Medical education should develop robust training programs in areas of need and these sites should get incentives to do so."

"The system should develop financial and resource support for smaller clinics and hospitals, which often serve vulnerable patients."

"Often, it may be beneficial to bring health care to individuals who are vulnerable rather than having them overcome barriers to present at a health care institution."

SDH, social determinant of health.

Populations classified as disabled ${ }^{53}$, immigrants ${ }^{54}$, rural $^{55}$, and racial minorities ${ }^{56}$ were the select vulnerable groups discussed at the Summit, as outlined in Table 2. Dr. Somnath Saha further highlighted the ways in which multiple axes of social disadvantages (eg, gender, income, ethnicity)—also known as intersectionality ${ }^{57}$ - compound health inequities. 
Nearly every Summit speaker expressed a need to partner with community organizations to address policies upholding societal inequities. For this to happen, Dr. Denise Rodgers asserted that a paradigm shift-one where medicine views systemic and racial injustice as a health issue ${ }^{58}$-must occur first. She proposed that an initial step in this paradigm shift is critical self-consciousness ${ }^{58}$ of unjust structures in health care and society; educational tools such as implicit association tests could help providers identify prejudices ${ }^{59}$ and mitigate the impact of those biases at the patient level. ${ }^{60}$ Summit participants expressed this self-awareness to be a necessary precursor to applying a broader institutional equity lens that could eventually encourage antiracism training in medical education, equitable hiring policies within institutions, and analysis of intersectional identity data in research to gradually dismantle the determinants of equity.

\section{Economics and Policy}

The ability of primary care to effectively address upstream determinants of health depends on the capacity to pay for these interventions, as evidenced by the key themes outlined in Table 3 . The predominant payment structure in the US health care system is driven by volume of clinical services (ie, fee for service) rather than value of care. ${ }^{28}$ The Affordable Care Act and, more recently, the Medicare Access and CHIP Reauthorization Act, encourage value-based care by supporting alternate payment models that shift toward prospective, capitated payments and may offer flexibility for practices to invest in interventions to alleviate disparities. ${ }^{61,62}$ Craig Hostetler explained how Oregon's involvement in the Comprehensive Primary Care Initiative ${ }^{63}$, which provided to clinics a riskadjusted, capitated per-member per-month payment representing $>80 \%$ of their revenue ${ }^{64}$, offered resources to expand primary care teams to screen for SDHs, implement novel SDH interventions, and partner with community organizations.

Risk-adjusted payments help guard against "cherry-picking" lower-complexity patients and/or underutilizing appropriate services in capitated models. Risk adjustments traditionally include individual-level risks, such as age and comorbidities, without accounting for social or community-level risk factors. ${ }^{65-68}$ Drs. Andrew Bazemore and Robert Phillips explained how payments that adjust for both patient-level SDHs and community vital signs ${ }^{43,48}$ could equip primary care physicians serving vulnerable populations with more resources to better address SDHs, pointing to the United Kingdom and New Zealand as bright spots that could guide and inform implementation in the United States. ${ }^{69,70}$

\section{Social Accountability}

As primary care interventions and payment models begin addressing SDHs, appropriate metrics are necessary to evaluate improvements toward health equity. Sonali Balajee discussed how social accountability - "the capacity to respond to society's priority health needs and health system" - could provide this equity lens. ${ }^{71}$ Whereas social responsibility within medicine aims to attain outcomes defined by health care organizations, social accountability aspires to define metrics and success with communities.

Policies that hold primary care accountable to society and monitor equity-related outcomes could be institutionalized if they are implemented across all sectors of health care-from medical education to clinical practices to administrations. An example in the medical education realm: while social responsibility may develop community medicine rotations to provide exposure to SDHs, social accountability requires the involvement of community organizations in the creation of the curriculum and measures the number of residents with sustained participation after residency. Summit participants identified the development of SDH interventions, hiring practices in professional organizations, and health equity research goals as targets for applying social accountability.

\section{Discussion}

The Starfield Summit renewed our commitment to Dr. Starfield's legacy, affirming the significance of primary care in health care systems, while emphasizing the specific and unique role for primary care in advancing health equity, which Dr. Starfield recognized as critical. To fulfill this role, we must progress from identifying existing inequities toward implementing feasible interventions to address them. Based on Summit speakers' presentations and participant discussions, we identified key actions encompassing the Summit's 4 domains, outlined in Table 4; these include implementing EHR-based tools that support SDH monitoring, 
Table 3. Brainstorming Themes Regarding Economics and Policy, as Discussed at the 2017 Starfield Summit

Themes of Starfield Summit Participants' Discussion on Economics and Policy

Representative Statements from Group Discussion Reflecting Theme

Health equity research should move from studying disparities and toward implementing solutions.

"Individuals and systems are frustrated about collecting health disparity and health equity data without established evidence-based mechanisms with which to act on data."

"The field of implementation science provides a conceptual framework to take existing knowledge about health disparities and demonstrate interventions that promote health equity."

"Health equity policies should be driven by attainable patient-oriented outcomes."

Health equity interventions should balance both individual and community-level risk factors.

"Individuals living in the same zip code can have vastly different social determinants of health."

"Care decisions should be informed by both immediately ascertainable individual medical data and historical community-level public health data."

"Real-time public health data streams could make social determinants data more relevant and actionable."

Solutions to address health equity should use a team-based approach.

Health care payments should be risk-adjusted for sociologic data.

Redistributing payments from health care to the social service sector supports health equity work.

Alternative payments for health equity work in primary care should be pursued.

Primary care should influence political structures that heavily impact health equity.

"Individuals from the community, as health workers, have the potential to understand community needs and effectively connect patients with resources."

"We need to think about expanding the workforce to address SDHs. . . Data from HealthLeads shows that one-time passive referrals are much less successful than ongoing coaching."

"Electronic health records limit data-sharing between systems, but understanding how individuals use various sectors [eg, clinic vs. hospital] is crucial to coordinate care."

"Enhanced payment models need to incorporate a marker for social complexity and its impact on health outcomes."

"Centers for Medicaid and Medicare and other private groups are exploring how to operationalize socioeconomic status in healthcare payments."

"Other countries' [eg, New Zealand, United Kingdom] experiences with social deprivation index-linked payment adjustments could inform US interventions."

"Primary care clinics may not be the ideal location to address social determinants of health, despite the fact that primary care intimately interacts with the social issues that affect peoples' lives."

"The social services and primary care health system must work in collaboration to gather health equity data and subsequently act upon social determinants."

"Enhanced payment models for social complexity should pay for appropriate health care and appropriate community-based services."

"Alternative payment models will increasingly hold health care delivery organizations accountable for social factors outside of the clinical setting, which may produce dangerous disincentives to care for socially disadvantaged patients."

"Innovative financing mechanisms, such as social impact bonds and benefit corporations, may provide avenues for private-sector investment in health equity."

"Future ideas should focus on creating public-private partnerships and incentivize these relationships for private companies."

"Globally, there appears to be a threat from government structures to move health systems away from people-centered services."

"Our system needs leaders who embody the ethics of equity and this may involve addressing political realities."

"We need to move beyond a profit-driven system to one that is rooted in morality."

SDH, social determinant of health. 
Table 4. Implications for Action Based on Themes Discussed at the 2017 Starfield Summit

\begin{tabular}{|c|c|}
\hline Theme & Implications for Action \\
\hline Education & $\begin{array}{l}\text { Incorporate advocacy, community organizing, and relational leadership skills into medical education } \\
\text { to enable future health professionals to partner with communities to create social change. } \\
\text { Change admission policies for health professional institutions to prioritize recruiting individuals } \\
\text { from underrepresented populations and communities of need. } \\
\text { Improve didactic exposure to vulnerable groups in health professional education and provide in- } \\
\text { person experiences with these populations. }\end{array}$ \\
\hline Clinical practice & $\begin{array}{l}\text { Use validated screening tools to identify SDHs and social needs. } \\
\text { Create data-enabled teams and workflows to identify and address SDHs in the context of the } \\
\text { clinical setting. } \\
\text { Develop roles in team-based primary care that include creating meaningful partnerships with } \\
\text { community members and organizations (eg, community health workers, community organizers). } \\
\text { Examine each clinical encounter from the perspective of systemic injustice or structural violence. }\end{array}$ \\
\hline Research & $\begin{array}{l}\text { Partner with clinicians to develop and validate SDH screening tools; partner with educators to } \\
\text { develop and measure effectiveness of health equity curricular elements. } \\
\text { Focus on implementation science research that highlights characteristics of feasible, replicable } \\
\text { interventions that identify and address SDHs at the clinical level. } \\
\text { Develop and validate new metrics that gauge the impact of health equity interventions, with a focus } \\
\text { on implementing patient-centered outcomes (eg, self-efficacy, social connectedness, quality of } \\
\text { life). } \\
\text { Engage in research focused on integration of individual-level SDH data with population and public } \\
\text { health outcomes. }\end{array}$ \\
\hline Policy and advocacy & $\begin{array}{l}\text { Invest in community partnerships and health information technology to develop workflows that } \\
\text { improve data sharing between primary care, public health, and local social services. } \\
\text { Partner with patients and use their stories to advocate for policy change that positively affects } \\
\text { SDHs and their effects on health care. } \\
\text { Ensure that all institutional and policy decisions include an equity lens. } \\
\text { Advocate for alternative payment models that enable primary care delivery to integrate social } \\
\text { services and community partnerships, such as individual- and community-level risk adjustments } \\
\text { for SDHs. }\end{array}$ \\
\hline
\end{tabular}

SDH, social determinant of health.

refining these tools to enhance clinical decision making about SDHs, partnering with community organizations addressing health equity, equipping health care professional students with an equity mind-set, and applying a social accountability lens within our institutions.

Some of these goals are immediately actionable, but many others require a commitment to sustained and coordinated efforts among primary care clinicians, researchers, educators, and advocates, as well as policymakers and community organizations. Although the Summit showcased numerous primary care bright spots in achieving health equity, a paucity of research exists to guide how primary care can most effectively address SDHs on a wide scale, with innovations currently outpacing the evidence. $^{72}$

One central premise of the Summit was that primary care can identify opportunities to drive some societal efforts to advance equity, and primary care can complement the work already being done by community organizations with the unique assets it may offer. Over time, clinical-community partnerships could offer bidirectional learning that encourages innovation in SDH interventions and brings the rigorous implementation research necessary to examine scalability across populations. With the national movement toward developing learning health systems ${ }^{73,74}$, centering clinicalcommunity partnerships within those systems could promote an equity and social accountability lens that guides rapid development and translation of health equity evidence to clinical care, medical education, and communities.

\section{Conclusion}

Although much is known about what health inequities persist in the United States, coordinated efforts across sectors are necessary to intervene in them effectively. The time is now to build on Dr. Starfield's work, by embracing the significant role of primary care in addressing both medical and social ailments of our country, so that we can achieve health equity for all. 
The authors gratefully acknowledge formatting assistance from Amanda Delzer Hill of the Department of Family Medicine at Oregon Health \& Science University.

To see this article online, please go to: bttp://jabfm.org/content/ 31/2/292.full.

\section{References}

1. Starfield B, Shi L, Macinko J. Contribution of primary care to health systems and health. Milbank Q 2005;83:457-502.

2. Doohan N, Coutinho AJ, Lochner J, Wohler D, DeVoe J. "A paradox persists when the paradigm is wrong": Pisacano Scholars' reflections from the inaugural Starfield Summit. J Am Board Fam Med 2016;29:793-804.

3. OCHIN (2017). Available from: http://www.ochin. org. Accessed June 18, 2017.

4. Starfield Summit [homepage]. Available from: http:// www.starfieldsummit.com/. Accessed June 16, 2017.

5. Ignite [homepage]. Available from: http://www. ignitetalks.io/. Accessed June 16, 2017.

6. National Academies of Sciences, Engineering, and Medicine. Communities in action: pathways to health equity. Washington (DC): National Academies Press; 2017.

7. Minkler M. Introduction to community organizing and community building. In: Minkler M, ed. Community organizing and community building for health and welfare. Rutgers (NJ): Rutgers University Press; 2012: 5-26.

8. Shirley D. Community organizing for urban school reform. Austin: University of Texas Press; 1997.

9. Shlay AB, Whitman G. Research for democracy: linking community organizing and research to leverage blight policy. City Community 2006;5:153-71.

10. Rank MR. One nation, underprivileged. New York: Oxford University Press; 2004.

11. Subica AM, Grills CT, Villanueva S, Douglas JA. Community organizing for healthier communities: environmental and policy outcomes of a national initiative. Am J Prev Med 2016;51:916-25.

12. Geiger HJ. The meaning of community oriented primary care in an American context. In: Institute of Medicine (US) Division of Health Care Services; Connor E, Mullan F, eds. Community oriented primary care: new directions for health services delivery. Washington (DC): National Academies Press; 1983:73-114.

13. Geiger HJ. The first community health centers: a model of enduring value. J Ambul Care Manage 2005;28:313-20.

14. Rosen G. What is social medicine? A genetic analysis of the concept. Bull Hist Med 1947;21:674-733.

15. Green LA, Fryer GE, Yawn BP, Lanier D, Dovey SM. The ecology of medical care revisited. N Engl J Med 2001;344:2021-5.
16. Nutting PA. Community-oriented primary care: from principle to practice. Albuquerque: University of New Mexico Press; 1990.

17. National Commission on Community Health Services. Health is a community affair: report of the National Commission on Community Health Services. Cambridge (MA): Harvard University Press; 1966.

18. Stephens GG. Remembering 40 years, plus or minus. J Am Board Fam Med 2010;23(Suppl 1):S5-10.

19. Stephens GG. Family medicine as counterculture. Fam Med 1989;21:103-9.

20. World Health Organization. Declaration of AlmaAta. International Conference on Primary Health Care; Alma-Ata, USSR; September 6-12, 1978.

21. Starfield B, Shi L. Policy relevant determinants of health: an international perspective. Health Policy 2002;60:202-21.

22. Shi L, Macinko J, Starfield B, Politzer R, Xu J. Primary care, race, and mortality in US states. Soc Sci Med 2005;61:65-75.

23. Starfield B. The hidden inequity in health care. Int J Equity Health 2011;10:15.

24. Das A. How does race get "under the skin"? Inflammation, weathering, and metabolic problems in late life. Soc Sci Med 2013;77:75-83.

25. Proctor BD, Semega JL, Kollar MA. Income and poverty in the United States: 2015. Washington (DC): US Census Bureau; 2016.

26. McDonough P, Duncan GJ, Williams D, House J. Income dynamics and adult mortality in the United States, 1972 through 1989. Am J Public Health 1997;87:1476-83.

27. Zumbrun J SAT scores and income inequality: how wealthier kids rank higher. Wall Street Journal, October 7, 2014. Available from: https://blogs.wsj.com/ economics/2014/10/07/sat-scores-and-incomeinequality-how-wealthier-kids-rank-higher/. Accessed May 15, 2017.

28. World Health Organization (WHO). More health for the money. In Health systems financing: the path to universal coverage. Geneva: WHO;2010:72-5.

29. Katerndahl D, Wood R, Jaén CR. Family medicine outpatient encounters are more complex than those of cardiology and psychiatry. J Am Board Fam Med 2011;24:6-15.

30. Beasley JW, Hankey TH, Erickson R, et al. How many problems do family physicians manage at each encounter? A WReN study. Ann Fam Med 2004;2: 405-10.

31. Bradley EH, Elkins BR, Herrin J, Elbel B. Health and social services expenditures: associations with health outcomes. BMJ Qual Saf2011;20:826-31.

32. Institute of Medicine. Public health: exploring integration to improve population health. Washington (DC): National Academies Press; 2012. 
33. Berwick DM, Nolan TW, Whittington J. The triple aim: care, health, and cost. Health Aff (Millwood) 2008;27:759-69.

34. Davis K, Stremikis K, Schoen C, Squires D. Mirror, mirror on the wall, 2014 update: how the US health care system compares internationally. New York: Commonwealth Fund; 2014. Available from: http:// www.commonwealthfund.org/publications/fundreports/2014/jun/mirror-mirror. Accessed January 23, 2018.

35. National Research Council; Committee on Population. US health in international perspective: shorter lives, poorer health. Washington (DC): National Academies Press; 2013.

36. National Institute of Health Care Management Foundation. The concentration of health care spending. Washington (DC): National Institute of Health Care Management Foundation; 2012.

37. Berenson J, Doty MM, Abrams MK, Shih A. Achieving better quality of care for low-income populations: the roles of health insurance and the medical home in reducing health inequities. New York: Commonwealth Fund; 2012.

38. Counsell SR, Callahan CM, Clark DO, et al. Geriatric care management for low-income seniors. JAMA 2007;298:2623-33.

39. Richard L, Furler J, Densley K, et al. Equity of access to primary healthcare for vulnerable populations: the IMPACT international online survey of innovations. Int J Equity Health 2016;15:64.

40. Thomas SB, Quinn SC, Butler J, Fryer CS, Garza MA. Toward a fourth generation of disparities research to achieve health equity. Ann Rev Public Health 2011;32:399-416.

41. Institute of Medicine of the National Academies, Committee on the Recommended Social and Behavioral Domains and Measures for Electronic Health Records. Capturing social and behavioral domains in electronic health records: phase 2. Washington (DC): National Academies Press; 2014.

42. Gottlieb LM, Tirozzi KJ, Manchanda R, Burns AR, Sandel MT. Moving electronic medical records upstream: incorporating social determinants of health. Am J Prev Med 2015;48:215-8.

43. DeVoe JE, Bazemore AW, Cottrell EK, et al. Perspectives in primary care: a conceptual framework and path for integrating social determinants of health into primary care practice. Ann Fam Med 2016;14:104-8.

44. Institute for Alternative Futures. Community health centers leveraging the social determinants of health. Alexandria (VA): Institute for Alternative Futures; 2012.

45. American Academy of Pediatrics. Social determinants of health. Available from: https://www. aap.org/en-us/advocacy-and-policy/aap-healthinitiatives/Screening/Pages/Social-Determinantsof-Health.aspx. Accessed June 16, 2017.
46. Centers for Medicare \& Medicaid Services. Accountable health communities model. Available from: https://innovation.cms.gov/initiatives/AHCM. Accessed June 16, 2017.

47. Bazemore AW, Cottrell EK, Gold R, et al. "Community vital signs": incorporating geocoded social determinants into electronic records to promote patient and population health. J Am Med Inform Assoc 2015;23:407-12.

48. Hughes LS, Phillips RL, DeVoe JE, Bazemore AW. Community vital signs: taking the pulse of the community while caring for patients. J Am Board Fam Med 2016;29:419-22.

49. Yaggy SD, Michener JL, Yaggy D, et al. Just for Us: an academic medical center-community partnership to maintain the health of a frail low-income senior population. Gerontologist 2006;46:271-6.

50. Herxheimer A, Ziebland S. The DIPEx project: collecting personal experiences of illness and health care. In: Hurwitz B, Greenhalgh T, Skultans V, eds. Narrative research in health and illness. Malden (MA): Blackwell; 2004: 115-31.

51. Oregon Health Authority. Community assessment. Available from: http://www.oregon.gov/oha/ PH/PREVENTIONWELLNESS/HEALTHY COMMUNITIES/COMMUNITYPLANNING/ Pages/community-assessment.aspx. Accessed September 18, 2017.

52. Graham H. Social determinants and their unequal distribution: clarifying policy understandings. Milbank Q 2004;82:101-24.

53. Havercamp SM, Scott HM. National health surveillance of adults with disabilities, adults with intellectual and developmental disabilities, and adults with no disabilities. Disabil Health J 2015;8:165-72.

54. Derose KP, Escarce JJ, Lurie N. Immigrants and health care: sources of vulnerability. Health Aff (Millwood) 2007;26:1258-68.

55. Hartley D. Rural health disparities, population health, and rural culture. Am J Public Health 2004; 94:1675-8.

56. Nelson AR, Stith AY, Smedley BD, eds.. Unequal treatment: confronting racial and ethnic disparities in health care. Washington (DC): National Academies Press; 2002.

57. Caiola C, Docherty S, Relf M, Barroso J. Using an intersectional approach to study the impact of social determinants of health for African-American mothers living with HIV. ANS Adv Nurs Sci 2014;37: 287-98.

58. Hardeman RR, Medina EM, Kozhimannil KB. Structural racism and supporting black lives-the role of health professionals. N Engl J Med 2016;375: 2113-5.

59. Devine PG, Forscher PS, Austin AJ, Cox WT. Long-term reduction in implicit race bias: a prejudice habit-breaking intervention. psychology Exp Soc Psychol 2012;48:1267-78. 
60. Burgess D, Van Ryn M, Dovidio J, Saha S. Reducing racial bias among health care providers: lessons from social-cognitive psychology. medicine Gen Intern Med 2007;22:882-7.

61. Gold SB, Park B. Effective payment for primary care. An annotated bibliography. Available from: https:// www.graham-center.org/content/dam/rgc/documents/ publications-reports/reports/StarfieldSummit\%20 Annotated\%20Bibliography_Payment-FIN.pdf. Accessed June 24, 2017.

62. Betancourt JR. Ushering in the new era of health equity. Health Affairs Blog, October 31, 2016. Available from: http://healthaffairs.org/blog/2016/10/31/ ushering-in-the-new-era-of-health-equity/. Accessed June 24, 2017.

63. Centers for Medicare \& Medicaid Services. Comprehensive primary care initiative. Available from: https://innovation.cms.gov/initiatives/comprehensiveprimary-care-initiative/. Accessed September 19, 2017.

64. Hostetler C. ACA opened the door for payment reform and practice transformation to address SDoH, now what? Starfield Summit II, Portland, OR, April 24, 2017.

65. Woolf SH, Johnson RE, Phillips RL Jr, Philipsen M. Giving everyone the health of the educated: an examination of whether social change would save more lives than medical advances. Am J Public Health 2007;97:679-83.

66. Hämmig O, Bauer GF. The social gradient in work and health: a cross-sectional study exploring the re- lationship between working conditions and health inequalities. BMC Public Health 2013;13:1170.

67. World Health Organization. The economics of social determinants of health and health inequalities: a resource book (vol. 3700). Geneva: World Health Organization; 2013.

68. National Academies of Sciences, Engineering, and Medicine. Accounting for social risk factors in Medicare payment: criteria, factors, and methods. Washington (DC): National Academies Press; 2016.

69. Salmond CE, Crampton P. Development of New Zealand's deprivation index (NZDep) and its uptake as a national policy tool. Can J Public Health 2012; 103(8 Suppl 2)S7-11.

70. Joynt KE, De Lew N, Sheingold SH, Conway PH, Goodrich K, Epstein AM. Should Medicare valuebased purchasing take social risk into account? N Engl J Med 2016;376:510-3.

71. Boelen C. Why should social accountability be a benchmark for excellence in medical education? Educ Med 2016;17:101-5.

72. Gottlieb LM, Wing H, Adler N. A systematic review of interventions on patients' social and economic needs. Am J Prev Med. 2017;53:719-29.

73. Greene SM, Reid RJ, Larson EB. Implementing the learning health system: from concept to action. Ann Intern Med 2012;157:207-10.

74. Grumbach K, Lucey CR, Johnston SC. Transforming from centers of learning to learning health systems: the challenge for academic health centers. JAMA 2014;311:1109-10. 